\title{
O Imaginário do Céu e do Inferno em Carlos D. de Andrade
}

\author{
Enivalda Nunes Freitas e Souza (UFU)
}

\begin{abstract}
RESUMO: Mesmo quando a poesia de Drummond evoca a fé provinda da tradição judaico-cristã, pode-se afirmar que o poeta mantém-se alheio à inquietação religiosa, desenvolvendo uma postura de união dos contrastes permeada pela ironia e pelo humorismo que lhe são peculiares. É o que se verifica no seu poema "Casamento do céu e do inferno", de Alguma poesia, por meio de símbolos, imagens e mitos. Neste ensaio, pretende-se conjugar o imaginário deste poema ao ideário estético do Modernismo e sua atitude de consagração das formas dissonantes.
\end{abstract}

PALAVRAS-CHAVE: Drummond; Céu e inferno; Milton, Blake.

ABSTRACT: Even when the poetry of Drummond evoques the faith from jewishchristian tradition, one can assume that the poet is apart from any religious anxiety. He develops although an attitude which joins contrasts, and his poetry is transversed by a proper irony and sense of humour. That's one can see in his poem "Casamento do céu e do inferno" ("Marriage of Heaven and Hell"), from the book Alguma Poesia (Some Poetry), in which the poet uses symbols, images and myths. The aim of this paper is to unite the imaginary of the above poem to the aesthetical ideas of the Modernism within its attitude of consecration of the dissonant forms.

KEYWORDS: Drummond; Heaven and Hell; Milton; Blake.

Escrito entre 24 e 30, Alguma poesia ainda ostenta caráter de batalha, pois pode ser lido como um combate ferrenho travado entre as concepções clássicas de mundo e de poesia e o mundo moderno, cuja linguagem revela as sete faces do indívíduo do século XX. Neste livro, ainda vive-se o tempo em que "o anjo bom" quer matar "o anjo mau" e jogar "seu corpo no rio", conforme versos do "Poema da purificação", o último de Alguma poesia. $\mathrm{O}$ anjo mau vencido na batalha tinha um sangue "que não descorava", tão forte que todos os peixes morreram. Contudo, aparece outro anjo, iluminado, para clarear o mundo e pensar "a ferida do anjo batalhador." Mas, afinal, o que anunciam, o que fazem tantos anjos na terra de Drummond? Como sabemos, é o anjo torto que abre Alguma poesia; mas quem encerra é um anjo iluminado, que vem para pensar a ferida do anjo batalhador. No penúltimo poema de Alguma poesia, Jesus 
dorme "sonhando com outra humanidade", cansado de tanto pedido. Desta forma, tendo anjos bons e anjos maus livre trânsito em sua poesia, não é difícil perceber que o poeta, mais do que afastar as forças contrárias, promove uma comunhão entre as contradições, um verdadeiro "casamento do céu e do inferno", como havia feito o poeta William Blake, dentro do mesmo espírito de inquietação e iconoclastia de que se reveste Drummond nestes tempos combativos do Modernismo. Acredito que os anjos de Drummond anunciam um trajeto mais livre para o homem, como também reforçam o anseio libertador da poesia da década de 20. Para engendrar esse caráter revolucionário comportamental e estético, não se pode perder de vista o gauche de Drummond ou o Satã de William Blake e de John Milton. Contudo, é um equívoco pensar que Drummond sela pacto com Satã, tampouco que se compromete com Deus. No fundo e no fim do poema, lá estão o humor e a ironia isentando o poeta de qualquer partidarismo comprometedor. Em poemas como "Infância" e "No meio do caminho", o poeta funde novos e velhos estilos de vida e de poesia, espantando o tédio e o estabelecido, e instaurando uma nova ordem.

O poema "Casamento do céu e do inferno", o terceiro de Alguma poesia, é suficiente para provocar algumas reflexões sobre o poeta itabirano e sobre aqueles anos decisivos para a poesia:

\section{CASAMENTO DO CÉU E DO INFERNO}

No azul do céu de metileno a lua irônica diurética

é uma gravura de sala de jantar.

Anjos da guarda em expedição noturna velam sonos púberes espantando mosquitos de cortinados e grinaldas.

Pela escada em espiral diz-que tem virgens tresmalhadas, incorporadas à via-láctea, vaga-lumeando...

Por uma frincha

o diabo espreita com o olho torto.

Diabo tem uma luneta

que varre léguas de sete léguas 
e tem o ouvido fino

que nem violino.

São Pedro dorme

e o relógio do céu ronca mecânico.

Diabo espreita por uma frincha.

Lá embaixo

suspiram bocas machucadas.

Suspiram rezas? Suspiram manso,

de amor.

E os corpos enrolados

ficam mais enrolados ainda

e a carne penetra na carne.

Que a vontade de Deus se cumpra!

Tirante Laura e talvez Beatriz,

o resto vai para o inferno.

(Carlos Drummond de Andrade. Alguma poesia)

De súbito, a objetivação, o caráter "anti-romântico (um céu de metileno, um retrato de lua). Penso que desde já se estabelece o princípio do casamento entre o "baixo" e o "elevado", melhor, entre duas ordens que se supõem distantes e antagônicas: a lua é deslocada da imaginação para tornar-se uma paisagem morta. Nesse deslocamento ela perde sua aura idealizada, intangível, e se converte num simulacro (gravura) desprovido de qualquer traço sentimental. A lua sem subjetividade, sem emoção. A lua desce ao cotidiano, não mais alimenta paixões (quase sempre platônicas) nem consola com sua solidão as almas inquietas: a lua (antes, tão metafísica) faz-se enfeite do espaço que serve à necessidade da mais prosaica materialidade humana: a sala de jantar. A lua vem abaixo e compõe o prosaísmo do diaa-dia. De forma contundente, esses versos ainda exalam combate, estranhamento, choque, e ostentam, claramente, uma postura arrivista, sinal de que a "ordem" ainda é ditada por outras leis que não sejam as da liberdade, da reflexão, da criatividade, da materialidade. Neste momento, as formas modernas ainda não estão sedimentadas, ainda é preciso criar um céu de metileno e uma lua irônica/diurética.

$\mathrm{Na}$ segunda estrofe, "anjos da guarda em expedição noturna" guardam sonos púberes espantando mosquitos. Há um solavanco na passagem da primeira para a segunda estrofe: o poeta sai da sala de jantar e penetra no quarto, sobrepondo à "lua 
irônica" "anjos da guarda" e "sonos púberes". Esta aparente descontinuidade imagética exemplifica a observação feita por Mário de Andrade sobre Alguma poesia: "Poesia sem água corrente, sem desfiar e concatenar de idéias e estados de sensibilidade, apesar de toda construída sob a gestão da inteligência. Poesia feita de explosões sucessivas. Dentro de cada poema as estrofes, às vezes os versos, são explosões isoladas" (1992: XXXVII).

Entrecruzando estas "explosões sucessivas", estão a inteligência e a sensibilidade de Drummond, segundo conclusão de Mário de Andrade. Assim é que após "a lua irônica/diurética" vêm os "sonos púberes" e, ao final, percebe-se que não há “explosões isoladas". Sob patrulhamentos e vigilâncias, as virgens (os sonos púberes) parecem repousar em paz. Se tomarmos, como tantas vezes o fazemos nas leituras de poesia, esses "sonos púberes" como metonímia (???) da virgem, poderíamos reconhecer aí a imagem do eterno feminino que muito bem pode simbolizar a poesia. Então, poderíamos ver os mosquitos como a poesia moderna e sua disposição em penetrar o véu que protege e separa a virgem/poesia de tradição clássica do reino deste mundo. $\mathrm{O}$ elevado continua descendo e se familiarizando, em evidência de que as distâncias e as contradições se encurtam, se aproximam. A lua desce e os anjos passeiam pela terra: "Anjos da guarda em expedição noturna". Os guardiões da moral e dos bons costumes, na tentativa de perpetuar a ordem vigente impõem as regras, fecham o cerco, para conduzir a virgem/poesia dentro da reta via.

Mas eis que no meio do caminho desse mundo ordeiro surge uma escada em espiral, por onde as virgens fogem, por onde a linguagem escapa. Instaura-se, assim, uma transitividade entre duas forças, entre duas instâncias, reforçada pela imagem espiral da escada: anjos descem à terra, virgens sobem ao céu. A espiral representa "a relação entre a unidade e a multiplicidade" e encerra, também, a "tentativa de conciliar a roda das transformações" (CIRLOT 1984: 241), haja vista que ela retorna ao mesmo ponto, mas num nível mais alto. Podemos relacionar essa imagem à idéia de movimento que marca a intelectualidade daquela época, expressando a insatisfação com a poesia ocupando sempre a mesma posição, perpetuando a pasmaceira de uma estética sem novidade, vazia das tensões que caracterizam o ser humano. O momento é de intensidade, de cumplicidade da poesia, como explica Drummond: 
Meu verso é minha consolação.

Meu verso é minha cachaça.

Para louvar a Deus como para aliviar o peito,

queixar o desprezo da morena, cantar minha vida e trabalhos

é que faço meu verso. E meu verso me agrada

Meu verso me agrada sempre... (1992: 33)

O ponto confluente desta escada espiralada é a poesia, mas uma poesia cheia de voltas, em movimento, agregadora de todos os sentimentos e atividades humanos, uma poesia liberta do que não é libertação. A espiral, em seu movimento ascendente, ao mesmo tempo em que recupera os mesmos elementos, coloca-os num nível mais alto. Assim, as virgens rompem o cerco e "tresmalham" por esta escada. Toda fuga é um desejo de libertação, é desejo de transformar pela própria experiência. As virgens transviadas não são lançadas para baixo, para a condenação, mas "incorporadas à vialáctea", e por lá ficam "vaga-lumeando...". Estaria o poeta deslocando as virgens bilaqueanas, ainda que sensuais mas muito puras, para uma outra Via-láctea? Nesta vialáctea modernista, as virgens não cintilam estaticamente, mas, por ter a liberdade de vagar pela amplidão sem fim é que melhor espalham seu brilho, um brilho descontínuo (o vaga-lume acende e apaga), do homem moderno fragmentado. O conceito de movimento que se estabelece desde a primeira estrofe, e que já se anuncia explicitamente no título, vai-se revelando nos versos para além da temática da comunhão entre os opostos, quando paramos para observar a primeira expressão do verso "diz-que tem virgens tresmalhadas,". O prosaísmo, a espirituosidade e a graça do boato (para não dizer fofoca) da expressão "diz-que" evoca a ironia e o humor habituais da subjetividade de Drummond, que por sua vez se revelam eficientes armas de combate no campo das artes, conforme afirma Bosi: "o humor cortaria, no estado atual das artes, toda ligação com as formas e os significados vigentes. (...) Há um momento em que o poeta mostra não tomar a sério os valores de uma certa cultura, ou melhor, as relações entre forma e conteúdo que a dominam: é a hora da paródia" (1977: 164-5).

O poeta recusa a linguagem e o comportamento correntes ao inserir a fala do cotidiano e sugerir a insubmissão comportamental. Parodiar as convenções vigentes é a forma de pensar valores mais próximos às exigências contemporâneas, o que significa que o poeta tem uma consciência crítica de seu tempo e de sua arte, pois a intenção de seu olhar não é destrutiva, mas construtiva, talvez tenha, como o teve William Blake, a 
intenção de edificar uma Nova Jerusalém, "cidade mística sem pecado nem lei; cidade onde os opostos se perseguem e se conciliam... cidade onde se festeja o casamento do céu com o inferno.”, resume Bosi (1977: 162).

Os versos seguintes, da quarta estrofe, flagram o diabo espiando a terra com seu olho torto. Parece ser o mesmo "anjo torto/desses que vivem na sombra" que apareceu ao poeta por ocasião de seu nascimento. O que o diabo espreita? O que ele cobiça? Está o diabo querendo estabelecer a desordem, a transgressão, ser, enfim, o porta-voz do mal, fazendo jus à tradição judaico-cristã? Mas, se aqui se vive o paraíso, por que as virgens estão transviadas, antes mesmo da intervenção demoníaca? Então, não se pode falar de ausência de conflito nesse paraíso terreal; o diabo não quer estabelecer a desordem, mas participar dela, tornar as coisas mais energéticas, considerando que o mal é a fonte de energia, a fonte de toda liberdade criadora. Segundo Willian Blake, em seu poema "O matrimônio do céu e do inferno", "Bem é o passivo que obedece à razão. Mal, o ativo emanando energia / Bem é Céu. Mal, inferno.” O que leva o bardo inglês à conclusão de que o céu é o inferno, e o inferno, por ser a fonte da energia e da criatividade, por ser ativo e libertador, por desobedecer à razão, o verdadeiro céu. Neste sentido, é o olho torto do diabo drummondiano que enxerga longe, porque tem lente de aumento, capaz de vasculhar "léguas de sete léguas". É um olhar penetrante porque sem censura, corruptível porque quer romper com o estado de coisas. É a atitude de Drummond e de seus colegas naqueles idos de 20 , de olho nos costumes burgueses, na linguagem das ruas e na poesia que estava distante da efervescência cotidiana; poesia cuja ausência de agudeza não esquadrinhava as contradições do dia-a-dia. A poesia de Drummond é a que vê longe e a que ouve bem, pois o diabo "tem o ouvido fino / que nem violino.", seu ouvido é de uma agudeza tão grande que repercute na rima e na acentuação. Esta rima já é o espírito livre e traquina do diabo inserindo a liberdade, a energia, a criatividade, o humor catártico, assim como o fogo dado aos homens por Prometeu, que acendeu a criatividade dos homens. A apatia na terra e a disposição em experimentar novas situações é ressonânica da indolência reinante no céu: "São Pedro dorme / e o relógio do céu ronca mecânico.”, enquanto o diabo continua de olho na terra. Há uma situação que favorece a inserção do elemento transgressor: a censura fecha os olhos, pouco se interessa pela sorte das coisas que controla. O mesmo não acontece com o paraíso recriado por John Milton: sabendo das conspirações de Satã, Deus manda que o anjo 
Rafael, por meio do sonho, previna Eva da ameaça de corrupção. Após a queda, os anjos julgam-se culpados por terem permitido que Satã rompesse o cerco: "As angélicas guardas pressurosas/Silenciosas e tristes se mostravam", mas a vigilância "foi justificada mui de pronto." (MILTON 1970: 286). Em Drummond, parece que a vontade de Deus é que o homem caia em errância, a vontade é que a poesia, liberta da razão, do meticuloso e do convencional, instaure uma nova ordem. No Paraíso perdido, é Satã quem leva o conhecimento, a imaginação e a sensualidade ao homem. Após comerem do fruto, Adão e Eva "em alegrias nadam": “já imaginam que ... asas lhes cria / Com as quais voem desprezando a terra." Contudo, a primeira evidência do fruto libertador da transgressão é o despertar da luxúria, da lascívia: "E o carnal apetite lhes inflama./Sobre Eva lança Adão sôfregos olhos, / Ela com outros tais lhe corresponde; / No fogo da lascívia ambos se abrasam," (MILTON 1970: 277). A descrição do sexo libertador que foi possível pela ação satânica, em Milton, leva Blake a reconhecer no bardo inglês "um poeta autêntico", que "tinha parte com o Demônio, sem sabê-lo" (1987: 14). O diabo do olho torto, de tanto espreitar a terra, vislumbra aqui embaixo homens que também se esqueceram de Deus, pois de suas bocas machucadas não se ouvem mais rezas, e sim confissões de amor. É a santificação do prazer sexual, o culto do amor, a transformação do profano em sagrado. O corpo, tradicionalmente impuro, ocupa o lugar da alma. A sensualidade, que está ligada à sensorialidade humana, com seu poder energético e criador, livre da vigilância divina, eleva o homem ao infinito e o santifica, conforme afirma Blake: "Se as portas da percepção estivessem limpas, tudo se mostraria ao homem tal como é, infinito" (1987: 23). Segundo Blake, a maior virtude é quebrar regras, porque "Jesus era todo virtude, e agia por impulso, não por regras" (1987: 32). Unir os contrários: a razão e a energia, reconciliar a carne com o espírito, porque as tensões geram progresso e, em síntese, "Oposição é verdadeira Amizade" (1987: 29). Mas Drummond não se mostra preocupado com o espírito. É um momento em que o "baixo", o terreno, a materialidade significam mais. Portanto, a carne deve reconciliar-se consigo mesma: “e a carne penetra na carne.” É o mal convertendo-se em bem pelo seu princípio ativo que emana energia. Os corpos enrolados, que "ficam mais enrolados ainda" representam bem a comoção modernista, aquela que deixa o sujeito "comovido como o diabo". O homem vive a sua condição humana, e a poesia revela essa experiência. Como a lua e o céu perderam sua aura elevada e espiritual e se 
agregaram ao prosaísmo da existência humana, o homem também se revela em seus aspectos mais tendenciosos. Esta postura de valorizar a matéria, muito antecedente ao Modernismo, tem uma tradição que se perde no tempo, ainda que românticos mais ousados fizessem dela um grande achado, como é o caso, entre nós, de Álvares de Azevedo. Em seu "Prefácio" à segunda parte da Lira dos vinte anos, o poeta diz:

Há uma crise nos séculos como nos homens. É quando a poesia cegou deslumbrada de fitar-se no misticismo e caiu do céu sentindo exaustas as suas asas de oiro. O poeta acorda na terra. Demais, o poeta é homem (...) Tem nervos, tem fibra e tem artérias - isto é, antes e depois de ser um ente idealista, é um ente que tem corpo. E, digam o que quiserem, sem esses elementos, que sou o primeiro a reconhecer muito prosaicos, não há poesia. (AZEVEDO, 39)

De fato, nesta segunda parte de sua obra o poeta elege a lavadeira como musa, não larga o charuto, amaldiçoa o editor, a escassez de dinheiro e compara-se a uma lagartixa, dentre outras provas de que está acordado "na terra" e fazendo uma poesia que revele isso. No poema “É ela! É ela! É ela! É ela!”, o poeta mostra na lavadeira, por quem está apaixonado, a mulher real, demasiadamente vulgar, no lugar das musas idealizadas, porque é essa mulher palpável que realmente existe: “É ela! É ela! meu amor, minh`alma, / A Laura, a Beatriz que o céu revela..." Humor, ironia e sátira caracterizam essa poesia de reflexão que o coloca em sintonia com a modernidade, ao mesmo tempo em que faz dele um interlocutor de seu tempo. Drummond fecha a questão do "casamento do céu e do inferno" com versos humorísticos e reflexivos que caracterizam sua poesia, como postula Arrigucci Jr. em Coração partido, características sempre acompanhadas da "ambigüidade de tom decisiva na modulação dos temas de que tratam." (2002: 28) Com a contundente afirmativa "Que a vontade de Deus se cumpra!", verso que tanto pode referir-se à aceitação da sensualidade libertadora dos acontecimentos precedentes (virgens transviadas que vaga-lumeam, a concupiscência dos corpos enrolados) quanto à condenação irremediável desta mesma lascívia nos versos seguintes ("Tirante Laura e talvez Beatriz, / o resto vai para o inferno"), Drummond escapa pela estreita e sutil frincha da ambigüidade que coloca no inferno muito mais a idéia de um paraíso terreal. Segundo Álvares de Azevedo, poeta que desliza sempre para a modernidade, não se pode chamar de inferno um lugar em que há 
mulheres: "No inferno estão suavíssimas belezas, / Cleópatras, Helenas, Eleonoras; / Lá se namora em boa companhia, / Não pode haver inferno com Senhoras!" Se Álvares de Azevedo elenca as graças que serão encontradas no inferno, Drummond aponta as únicas que não estarão lá: "Laura e talvez Beatriz". Representações máximas da beleza idealizada e espiritualizada, essas mulheres estabeleceram a tradição do eterno feminino ligado à pureza e à castidade, o que, a princípio, não levaria a distinções relevantes no que concerne à reputação ilibada de ambas, a ponto de o poetagauche colocar em dúvida a beatitude de Beatriz. O "talvez" seria apenas mais uma pitada de humor para acentuar a ambigüidade do verso antecedente e colocar mais uma pedra na "reta via" do leitor. O artigo de Livio Panizza (UERJ), "Beatriz e Laura em confronto", ainda que não desfaça o desconforto desse julgamento por demais severo com Beatriz (ela é e sempre será a manifestação da graça divina), esclarece que antes de atingir o amor sublimado, Beatriz inspirou o amor carnal:

Do amor carnal, da paixão presente no início da Vita Nuova eleva-se a expressões de amor mais elaboradas, próprias da "charitas", reforçadas pelas experiências intelectuais do Convívio até chegar a formas espiritualizadas e sublimadas na Divina Comédia. Dante, no início da Vita Nuova amou Beatriz segundo os cânones do amor cortês, cantando a beleza do seu olhar, a beleza de sua face, a graça e a modéstia de seus gestos. Nesse primeiro encontro Dante é presa de turbações e de angústias que invadem até seus sonhos, mas ao término da obra seus sentimentos são sublimados.

Quanto a Laura, ela nunca foi uma mulher real, mas um modelo de beleza, “ o modelo do qual o pintor se apaixona, não como homem, mas como pintor, preocupado muito mais em representá-la do que possuí-la”, conclui Panizza.

Ao final da leitura do poema, somos obrigados a repensar seu título e, para entendê-lo, reavaliar as ações da santíssima trindade que sustenta o texto: o homem, o diabo e Deus (representado por São Pedro). Vimos que São Pedro dorme, o diabo olha e o homem faz. As virgens se desgarram por conta própria, os homens trocam as profissões de fé pelas confissões de amor e vivem deliciosamente a sua luxúria, sem precisar que o diabo a propicie. Assim, o diabo perde seu posto, para o homem, de príncipe do desregramento e torna-se apenas espectador atento, desejoso de participar 
das ações humanas, porque nelas se reconhece. A ação diabólica é atenuada (o diabo está em cima e apenas vê) e o caráter demoníaco do homem é acentuado. Se no Paraíso perdidoSatã é a personagem principal e o homem a vítima de suas artimanhas, neste casamento drummondiano o homem é o portador do conhecimento que liberta, da energia criadora, por isso "a carne penetra na carne". Desta forma, não temos a reconciliação da carne com o espírito proposta por William Blake, e o poema de Drummond torna-se uma paródia ao "O matrimônio do céu e do inferno", quando a junção das tensões ainda precisava ser reclamada. O homem contemporâneo de Drummond já incorporou o espírito demoníaco, o que leva sua poesia a transitar entre dois mundos: o do combate, por estar dentro de uma tradição de ruptura, e o da paródia, porque seu olho torto vasculha além de seu tempo.

\section{OBRAS CITADAS}

ANDRADE, Carlos Drummond de. 1992. Poesia e prosa. Rio de Janeiro: Nova Aguilar.

ARRIGUCCI JR., Davi. 2002. Coração partido. Uma análise da poesia reflexiva de Drummond. São Paulo: Cosac \& Naify.

AZEVEDO, Álvares de. 1996. Poesias completas. Rio de Janeiro: Ediouro.

BLAKE, William. 1987. O matrimônio do céu e do inferno. Trad. José Antônio Arantes. São Paulo: Iluminuras.

BOSI, Alfredo. 1977. O ser e o tempo da poesia. São Paulo: Cultrix.

MILTON, John. 1970. Paraíso perdido. Trad. António José Lima Leitão. São Paulo: W. M. Jackson.

PANIZZA, Livio. 2004. "Beatriz e Laura em confronto". Cadernos do CNLF. Disponível emhttp://www.filologia.org.br/viiicnlf/anais/caderno04-06.html. Acesso em maio de 2006. 